\title{
ANTI-MULLERIAN HORMONE AS A MARKER FOR DIAGNOSIS OF POLYCYSTIC OVARY SYNDROME AND ITS FUNCTION AFTER LAPAROSCOPIC OVARIAN DIATHERMY
}

\author{
Amal Hossien Abou Saif, (1) Laila A. Ahmed ${ }^{(2)}$ and Amal Abdelaleem Morsy ${ }^{(3)}$ \\ ${ }^{(1)}$ Gynecology \& Obstetrics Department, ${ }^{(2)}$ Biochemistry Department and ${ }^{(3)}$ Clinical Pathology \\ Department, Faculty of Medicine, Al Azhar University Hospital
}

\section{ABSTRACT}

Background: Although the polycystic ovary syndrome (PCOS) is the most frequent endocrine disorder in women of reproductive age, its diagnosis remains one of the most challenging issues in endocrinology, gynecology, and reproductive medicine. The elevated levels of Anti-mullerian hormone (AMH) in the women of PCOS strongly suggested that serum AMH levels may be used in the diagnosis of this condition. Laparoscopic ovarian diathermy (LOD) frequently induces ovulation in patients with polycystic ovary syndrome (PCOS). The mechanism by which this effect occurs remains largely unexplained.

The aim of this study is to assess whether AMH could play a role in the diagnosis of PCOS and to measure changes in $(A M H)$ production in response to (LOD) to see whether this could explain the mechanism of action of (LOD).

Methods: This prospective study included 30 anovulatory women with PCOS and 10 ovulatory women as a control. All PCOS women underwent LOD. Blood samples were collected before and after LOD to measure plasma concentrations of Anti-Mullerian Hormone (AMH), estradiol (E2), gonadotrophins (FSH and LH), and testosterone. The number of early (at day 3 of the cycle) antral follicles ( $2-9 \mathrm{~mm}$ in diameter) were estimated by ultrasound scanning.

Results: The mean serum AMH level was about 3-folds higher in PCOS patients than in controls $(\mathrm{P}<0.001)$. Likewise, the 2- to 9-mm follicular numbers per ovary (FNPO) at U/S were 3-fold higher in PCOS patients than in controls $(\mathrm{P}<$ $0.001)$. It was significantly related to the serum AMH levels, both in controls $(r=0.370 ; P<0.022)$ and in patients $(r=$ $0.670 ; \mathrm{P}<0.0001)$. AMH was also positively related to the serum testosterone level in cases in comparison to controls ( $r=0.454$ and $P<0.0004$ in cases; versus $r=0.163$ and $P=0.288$ in controls). No significant correlation was observed between FSH, E2, BMI and AMH levels in PCOS patients and controls. In PCOS patients, the mean serum level of AMH differed significantly by ANOVA $(P<0.05)$ between those presenting either with amenorrhea $(n=10)$, oligoamenorrhea $(n=10)$ or regular cycles $(n=10)$; the former and the latter having the highest and the lowest values, respectively $(8.17 \mathrm{ng} / \mathrm{ml}$ and $16.8 \mathrm{ng} / \mathrm{ml}$ ). As expected, the 2- to $9 \mathrm{~mm}$ follicular number per ovary (FNPO ) followed the same trend in these three subgroups $(\mathrm{P}<0.05$ ), whereas age did not exert a statistically significant effect. Our data suggest that, high androgen (HA) is associated with higher serum AMH levels in PCOS patients with irregular cycles. Following LOD, there was a statistically significant reduction of mean plasma concentrations of AMH from the pre-operative values in the overall group of 30 women with PCOS $[8.2 \mathrm{ng} / \mathrm{ml}$ versus $12.2 \mathrm{ng} / \mathrm{ml}]$. Women who ovulated after LOD $(n=10)$ had a higher mean pre-LOD AMH level $[15.5 \mathrm{ng} / \mathrm{ml}]$ compared with that $[10.5 \mathrm{ng} / \mathrm{ml}]$ of patients ( $\mathrm{n}$ $=20$ ) who did not respond. After LOD there was a statistically significant reduction in LH: FSH ratio and the plasma concentrations of LH and testosterone. Plasma concentrations of FSH did not change after LOD.

Conclusions: Anti-Mullerian Hormone could be a valuable marker for diagnosis of polycystic ovary syndrome and improvement of its function after laparoscopic ovarian diathermy. The dramatic and significant reduction of Anti-Mullerian hormone after LOD especially in responders makes it likely that this hormone has a role to play in the mechanism of action of LOD. 


\section{INTRODUCTION}

Polycystic ovary syndrome (PCOS) is the most common endocrine disorder affecting $5-10 \%$ of women of reproductive age ${ }^{(1)}$, accounting for at least $75 \%$ of cases with anovulatory infertility ${ }^{(2)}$. It is characterized by a heterogeneous group of disorders that occur in varied combinations including clinical [oligomenorrhoca /anovulation, hirsutism, acne and elevated body mass index (BMI)], biochemical (elevated circulating androgens and/or $\mathrm{LH}$ and evidence of insulin resistance) and/or ultrasound features of polycystic ovaries (increased ovarian volume $>10 \mathrm{ml}$ and/or number of small follicles $>12^{(3)}$

Although the polycystic ovary syndrome (PCOS) is the most frequent endocrine disorder in women of reproductive age, its diagnosis remains one of the most challenging issues in endocrinology, gynecology, and reproductive medicine ${ }^{(4)}$.

The mechanism(s) leading to anovulation is (are) still poorly understood. For many years the excess in intraovarian androgens has been suspected to disturb folliculogenesis, through a proatretic effect on growing follicles ${ }^{(5)}$. However, more recent experimental data in rhesus monkeys strongly suggest that in fact, intraovarian androgens promote granulosa cell (GC) proliferation and inhibit apoptosis, especially in small follicles whose GCs are the richest in androgen receptors ${ }^{(6)}$. Accordingly, polycystic ovaries (PCOs) are characterized by an excessive number of growing follicles (2- to 3-fold that of normal ovaries), up to the stage of $2-5 \mathrm{~mm}$ in size (small antral follicles) ${ }^{(7)}$. This phenomenon is thought to result from an impaired action of FSH on the follicle cohort, whose mechanism(s) is (are) unclear ${ }^{(2)}$.

$\mathrm{AMH}$, also known as Mullerian inhibiting substance (MIS), has been mainly studied for its regulatory role in male sex differentiation. AMH, produced by the Sertoli cells of the fetal testis, induces the regression of the Mullerian ducts, the anlagen of the female reproductive tract $^{(8)}$. However. after birth, this sex-dimorphic expression pattern is lost and AMH is also expressed in granulosa cells of growing follicles in the ovary.

Anti-Mullerian hormone $\mathrm{AMH}$ is an ovarian product, a marker of ovarian reserve ${ }^{(9,10)}$ and is a local inhibitor of FSH action (11). Ovarian production of AMH is higher in PCOS patients compared with women with regular menstrual cycles ${ }^{(4,12)}$, probably due to an excess of antral follicles (13).

Ovarian surgery for ovulation induction has been used in the management of clomiphene citrate-resistant anovulatory women with PCOS. Various types of ovarian surgery have been employed (wedge resection, electrocautery, laser vaporization, multiple ovarian biopsies and others) and all procedures result in an altered endocrine profile after surgery. The mechanism behind the reversal of endocrinological dysfunction in PCOS after ovarian surgery remains incompletely understood ${ }^{(14)}$.

To establish the exact role of AMH in the pathophysiology of PCOS, we measured the plasma concentrations of AMH in a series of PCOS women before and after LOD. the aim of the present study was to assess: 1) whether AMH could play a role in the diagnosis of PCOS, and 2) to assess any change of Anti-Mullerian Hormone after LOD and if this hormone has any role to play in the mechanism of action of LOD. To the best of our knowledge, no studies have been published about the possible AMH changes after ovarian surgery in PCOS patients ${ }^{(14)}$.

\section{MATERIALS \& METHODS}

Subjects:

Thirty women with anovulatory infertility associated with PCOS who were scheduled for LOD were prospectively included in this study between 2005 and 2006. All women had polycystic ovaries According to The Rotterdam criteria, $2003^{(15)}$. The 
diagnosis of PCOS was based on the association of at least two of the three following criteria: 1) ovulatory disturbance, mainly oligomenorrhea or amenorrhea, 2) hyperandrogenism (IHA) as defined either clinically by hirsutism or severe acne/seborrhea, and/or biologically by a testosterone serum level greater than $0.7 \mathrm{ng} / \mathrm{ml}$, and 3) more than 12 follicles in the 2- to 9-mm range in each ovary at U/S and/or an ovarian volume higher than $10 \mathrm{ml}$. All women had previously failed to respond to incremental doses of clomifene citrate. All women gave informed consent for laparoscopic ovarian drilling using diathermy. U/S measurements were taken in real time, according to a standardized protocol, as previously described ${ }^{(13)}$.

\section{Controls:}

The control population consisted of 10 women who were infertile due to tubal and/or male infertility. No clinical biochemical or US evidences of PCOS.

\section{Collection of blood samples:}

Blood samples were taken from PCOS patients shortly before LOD at a random time in amenorrhoec women and early in the follicular phase (menstrual cycle day 2-4) in menstruating women. Further blood samples were obtained 1 week after surgery.

\section{Hormonal assays:}

The hormone assays for $\mathrm{FSH}, \mathrm{LH}$, testosterone and progesterone were performed using the electrochemiluminescence immunoassay " ECLTA" (eleisys 1010) Roch Diagnostics Corporation ,Manheim, Germany .

Serum AMH levels were assessed using the second-generation enzyme immunoassay AMH-EIA (reference A16507) provided by Immunotech (a Beckman Coulter company from Marseille, France) according to the supplier's instructions. A recombinant human $\mathrm{AMH}$ was used as a calibration standard to build a standard curve ranging from 0-12 $\mathrm{ng} / \mathrm{ml}$. Intra- and interassay coefficients of variation were less than 12.3 and $14.2 \%$, respectively.

\section{LOD}

The techniques of laparoscopic ovarian drilling used in this study have previously been published (16-18). A specially designed monopolar electrocautery probe, was used to penetrate the ovarian capsule at several points with the aid of a short burst of monopolar diathermy. The electrosurgical unit used was the Force 2 Valleylab electrosurgical generator (Valley lab Inc., Boulder, CO, USA). A monopolar coagulating current was used to make three to four punctures per ovary at a power setting of $40 \mathrm{~W}$ applied for $4 \mathrm{~s}$ per puncture.

\section{Post-operative monitoring for ovulation}

Following LOD, patients were followed for 6 weeks for cvidence of ovulation. Ovulation was diagnosed by serum progesterone $(25 n g / l)$ or by US monitoring of ovulation.

\section{Statistical analysis}

Plasma AMH values did not follow a normal distribution and were therefore compared using non-parametric statistical tests (Mann-Whitney U test, Spearman's correlation coefficient and ANOVA test). Other continuous data were normally distributed and were therefore compared using t-test. $P<0.05$ was considered the minimum level of significance.

\section{RESULTS}

The characteristics of 30 women with anovulatory infertility associated with polycystic ovary syndrome (PCOS) are shown in table I. The main clinical, biological, and U/S differences between PCO cases and controls are shown in table II. As expected, patients with PCOS had higher body mass index values, higher mean ovarian volume and higher serum levels of LH and testosterone, than controls. There was a trend toward lower FSH values in PCOS patients than in controls. The mean serum AMH level was about 3-fold higher in PCOS patients than in controls ( $P_{-}$0.001). Likewise, the 2- to 9-mm FNPO at U/S were about 3-fold higher in PCOS patients than in controls $(P<0.001)$. It was significantly related to the serum AMH levels, both in controls 
$(r=0.370 ; \quad P=0.022)$ and in patients $(r=0.670$; $\mathrm{P}=0.0001)$. AMH was also positively related to the serum testosterone level in cases in comparison to control $(r=0.454$ and $P=0.0004$ in cases; versus $r=0.163$ and $P=0.288$ in control) (table III). No significant correlation was observed between FSH, E2, BMI and AMH lcvels in PCOS patients and controls, sec table III.

In PCOS patients, the mean serum level of AMH differed significantly by ANOVA $(\mathrm{P}<0.05)$ between those presenting cither with amenorrhea $(n=10)$, oligoamenorrhea ( $n=10)$ or regular cycles $(n=10)$; the lormer and the latter having the highest and the lowest values, respectively, (table IV). As cxpected, the 2- to $9 \mathrm{~mm}$ FNPO followed the same in these three subgroups (ANOVA, $P<0.05$ ), whereas age did nol cxcrt a statistically significant effect (table IV). When the PCOS palients with abnormal cycles were gathered together $(n=20)$, we observed that the AMH levels varied significantly $(\mathrm{p}=0.03)$ according to the absence $(n=10)$ or the presence $(n=20)$ of $H A$, as defined by a serum level of testosterone above 0.7 $\mathrm{ng} / \mathrm{ml}$ and/ or clinically by hirsutism. Therefore, these data suggest that $\mathrm{HA}$ is associated with higher serum AMH levels in PCOS patients with irregular cycles, (table V).

\section{Laparoscopic ovarian diathermy and AMH in} PCOS:

Following LOD, there was statistically significant reduction ( $\mathrm{p}<0.001$ ) of mean plasma concentrations of AMH from the pre-operative values in the overall group of 30 women with PCOS $[(8.2 \mathrm{ng} / \mathrm{m}])$ versus (12.2ng $/ \mathrm{ml}$ )] (table VI). Women who ovulated after LOD $(n=10)$ had a significantly higher mean pre-LOD AMH level [15.5 $\mathrm{ng} / \mathrm{ml}]$ compared with that $[10.5 \mathrm{ng} / \mathrm{ml}]$ of Women $(\mathrm{n}=20)$ who did not ovulate. Table $\mathrm{V}$, summarizes other endocrine changes after LOD. The resulls show a statistically significant reduction in LH: FSH ratio and the plasma concentrations of $\mathrm{LH}$ and testosterone. Plasma concentrations of FSH did nol change after LOD.

Table I : Characteristics of 30 women with anovulatory infertility associated with polycystic ovary syndrome (PCOS).

\begin{tabular}{|l|c|}
\hline \multicolumn{1}{|c|}{ Characteristic } & Mean \pm SEM \\
\hline - Age (ycars) & $29.0 \pm 0.6$ \\
- Body mass index (BMI) $(\mathrm{kg} / \mathrm{m} 2)$ & $27.0 \pm 0.7$ \\
- LH (IU/I) & $8.0 \pm 0.9$ \\
- FSH (IU/l) & $5.6 \pm 0.2$ \\
- LH: FSH ratio & $1.4 \pm 0.2$ \\
- Testosterone (ng) & $0.73 \pm 0.2$ \\
- Ovarian volume & $12.5 \pm 1.1$ \\
\hline Menstrual cycle pattern & $\mathbf{n}(\%)$ \\
\hline Regular & $10(33)$ \\
Oligomenorrhoea: & $10(33)$ \\
Amenorrhoca: & $10(33)$ \\
\hline Hirsutism & $20(67)$ \\
Yes & $10(34)$ \\
No & \\
\hline Acne & $17(57)$ \\
Yes & $13(43)$ \\
No & \\
\hline Lnfertility & 25 \\
1ry & 5 \\
2ndry & \\
\hline
\end{tabular}


TABLE II: Main clinical, hormonal, and ultrasonographic differences between controls and patients with PCOS.

\begin{tabular}{|l|c|c|c|}
\hline & $\begin{array}{c}\text { Controls } \\
\left.\mathbf{n} \_10\right)\end{array}$ & $\begin{array}{c}\text { PCOS patients } \\
\left(\mathbf{n} \_10\right)\end{array}$ & P value \\
\hline Age (yr) & $28(22-35)$ & $29(22-36.4)$ & NS \\
BMI (kg/m2) & $23.4(18.2-31.8)$ & $27(19-39)$ & -0.01 \\
LH (IU/liter) & $3.7(2.1-5.9)$ & $8(3.3-14.9)$ & -0.001 \\
FSH (IU/iter) & $5.8(4.5-7.3)$ & $5.6(4.0-7.4)$ & -0.01 \\
\hline Testosterone & & & -0.001 \\
(ng/ml) & $0.3(0.17-0.45)$ & $0.53(0.25-0.83)$ & $0 / 001$ \\
AMH (ng/m)) & 2.9 ng (2.3-3.8) & $6.6 \mathrm{ng}(7.3-18)$ & -0.001 \\
Ovarian volume & 8.2 & $12.05 \pm 1.1$ & -0.001 \\
\hline 2- to 9- mm & & & -0.36 \\
follicle no. & $6.8(3.3-12.0)$ & $18.7(7.8-44.3)$ & $32(20-47)$ \\
E2 (pg/ml) & $30(20-52)$ & & \\
\hline
\end{tabular}

Values are expressed as the mean with the 5th-95th percentile range in parentheses. NS, Non significant.

TABLE III: Relationships between the AMH plasma level and BMI or other biological data (serum levels) in patients with PCOS and in controls.

\begin{tabular}{|l|c|c|c|c|}
\hline & \multicolumn{2}{|c|}{ PCO $(\mathrm{N}=30)$} & \multicolumn{2}{c|}{ Controls $(\mathrm{N}=10)$} \\
\cline { 2 - 5 } & $\begin{array}{c}\text { Correlation } \\
\text { coefficient }\end{array}$ & $\mathrm{P}$ & $\begin{array}{c}\text { Correlation } \\
\text { coefficient }\end{array}$ & $\mathrm{P}$ \\
\hline AMH, 2-9mm FN & 0.670 & 0.0001 & 0.370 & 0.022 \\
\hline AMH, FSH & 0.313 & 0.018 & 0.311 & 0.037 \\
\hline AMH, testosterone & 0.454 & 0.0004 & 0.153 & 0.288 \\
\hline AMH, E2 & 0.083 & 0.54 & 0.072 & 0.64 \\
\hline AMH, BMI & 0.061 & 0.66 & 0.280 & 0.048 \\
\hline
\end{tabular}

TABLE IV: AMH levels in patients with PCOS according to their menstrual status.

\begin{tabular}{|l|c|c|c|c|}
\hline Menstrual status & Regular cycles & Oligoamenorrhea & Amenorrhea & Pvalue \\
\hline No. of patients & 10 & 10 & 10 & - \\
\hline Age (yr) & $29.4(4.1)$ & $29.0(4.0)$ & $28.7(4.8)$ & - NS \\
\hline AMH (ng/ml) & $8.17(1.1)$ & $11.70(1.5)$ & $16.80(1.8)$ & -0.05 \\
\hline 2- to 9-mm FNPO & $15.2(4.9)$ & $18.6(9.4)$ & $25.9(13.3)$ & -0.05 \\
\hline
\end{tabular}

Values are expressed as the mean with the (SD).

NS, Non significant. 
Table V: Endocrine changes after laparoscopic ovarian diathermy (LOD) in 30 women with anovulatory infertility associated with polycystic ovary syndrome (PCOS). Data presented as mean \pm SEM.

\begin{tabular}{|l|c|c|c|}
\hline \multicolumn{1}{|c|}{ Plasma } & Before LOD & After LOD & $P$ \\
\hline LH (IU/l) & $12.2 \pm 0.9$ & $9.1 \pm 0.8$ & $<0.01$ \\
FSH (IU/l) & $4.8 \pm 0.2$ & $4.7 \pm 0.2$ & 0.496 \\
LH: FSH ratio & $2.6 \pm 0.2$ & $0.9 \pm 0.2$ & $<0.001$ \\
\hline Testosterone & & & $<0.001$ \\
(ng/ml) & $2.7 \pm 0.2$ & $2.2 \pm 0.1$ & $<0.001$ \\
AMH (ng/ml) & $12.2 \pm 0.3$ & $8.2 \pm 0.2$ & \\
\hline
\end{tabular}

\section{DISCUSSION}

PCOS encompasses a broad spectrum of clinical and biochemical characteristics, and, although the mechanisms leading to PCOS are still poorly understood, the common denominator is a disturbance in the selection of the dominant follicle resulting in anovulation. The defective selection mechanism results in an accumulation of small antral follicles, which contribute significantly to the production of $\mathrm{AMH}^{(3)}$.

In the present study, we have measured the circulating concentrations of $\mathrm{AMH}$ in 30 women with anovulatory infertility associated with PCOS and studied its association with the clinical, biological, and U/S features of this population and also, the effect of LOD on these levels.

The data showed that most PCOS women in this study as expected, had higher body mass index values and higher serum levels of LH, testosterone, than controls. There was a trend toward lower FSH values in PCOS patients than in controls.

The mean serum AMH level was about 3-fold higher in PCOS patients than controls and than the reported level in normal women ${ }^{(19)}$. Also, the mean 2- to 9-mm FNPO at U/S was 3-fold higher in PCOS patients than in control women. It was also significantly related to the serum AMH levels, both in controls and in patients.
In 2003, Fanchin et al; demonstrated that the antral follicle count was closely related to the serum AMH level on cycle d 3 in infertile women, in a stronger way than those obtained with other hormonal markers such as inhibin B, estradiol, or $\mathrm{FSH}^{(20)}$.

Later, several teams reported on a strong increase (2- to 4-fold) of serum AMH levels in PCOS patients, in close relationship with the increase in the small antral follicular number(FN) ${ }^{(19,21)}$.

Moreover, it was recently demonstrated that $\mathrm{AMH}$ levels remain relatively constant during the follicular phase and entire menstrual cycle ${ }^{(12,22)}$ and the measurement of serum AMH levels was highly reproducible from one cycle to another, a fact that underlines its robustness as a biological marker of the ovarian follicle status ${ }^{(23)}$.

Thus, all these data led to the conclusion that AMH could be the best available biological marker of the ovarian early antral $\mathrm{FN}$, both in fertile and infertile normoovulatory women and in PCOS patients.

In this study $\mathrm{AMH}$ was also positively related to the serum testosterone level in both groups $(r=0.225$ and $\mathrm{P}=0.03$ in controls; $\mathrm{r}=0.360$ and $\mathrm{P}=0.003$ in patients). No significant correlation was observed between FSH, E2, BMI and AMH levels in PCOS patients and controls.

This is in agreement with the previous report of 
(Eldar-Geva et.al.) $)^{(24)}$ that follicle number and testosterone levels independently correlated with AMH serum levels. These results suggest that the non visible pool of follicles may be further increased in the presence of increased androgen level. However, the mechanism behind the positive association between androgens and AMH in PCOS women requijes further studies ${ }^{(25)}$.

This lends support to the hypothesis of Jonard in $2004^{(26)}$ that AMH may be involved in the ovulatory disorder of PCOS patients and may have effects distinct from HA, through inhibition of the FSHdependant cyclic recruitment ${ }^{(27)}$ and/or aromatase activity ${ }^{(28)}$.

Moreover, we also showed in our study that, in patients with irregular cycles, the presence of $\mathrm{HA}$ was associated with a further increase of the AMH values.

This is in agreement with Laven et al.(2004)(21) who also reported a positive correlation between the cycle duration, the serum androgen levels, and AMH in PCOS patients. Our results also agree with those of La Marca et al; $2004^{(22)}$ showing that amenortheic women with PCOS had a higher mean serum AMH levels than their oligomenorrheic patients.

In conclusion, it can be proposed from the present study that single measurement of AMH in the early follicular phase in women with HA and/or oligo-anovulation could indicate to the clinicians the presence of $\mathrm{PCO}$ when reliable $\mathrm{U} / \mathrm{S}$ is not available. However, it must be kept in mind that neither a high value of AMH nor a high FNPO is per se is sufficient to ascertain PCOS. Both criteria need to be incorporated into the $\mathrm{PCO}$ diagnosis.

In the present study, no significant correlation was observed between FSH, E2, BMI and AMH levels in PCOS patients and controls.

\section{AMH and BMI:}

In this study, no significant correlation was observed between AMH and BMI. This comes in agreement with the studies of Pigny et al. (2003), and Laven et al. (2004) that showed that serum AMH levels do not seem to correlate with BMI and insulin levels ${ }^{(19,21)}$.

In contrast, in a small study, La Marca et al. $(2004)^{(22)}$ observed a positive correlation between serum AMH levels and the HOMA index, an insulin resistance index cakculated from fasting insulin and fasting glucose levels.

\section{AMH and FSH and E2.}

In this study, no significant correlation was observed between AMH and FSH nud E2 .

Durlinger et al. (1) found the absence of regulation of AMH by gonadotropins that was shown in both rodents and man, suggesting that AMH nets as at paracrine rather than a systemic factor, and thus is not part of a negative feedback loop with involvement of gonadotropins.

In a sludy done by Fanchin el a! $(2003)^{(20)}$, they found that AMH correlated more intensely with early antral follicular counts than did the other hormonal markers of follicular status (inhibin B, E2, FSH and $\mathrm{LH})$; the reasons for this striking phenomenon were unclear.

\section{The impact of LOD in PCOS:}

A-The impact of LOD on LH: FSH, LH and testosterone:

In this study, the results show a statisticalily significant reduction in LH: FSH ratio and the plasma concentrations of $\mathrm{LH}$ and testosterone after LOD

Van Santbrink ot al.(1997) stated that chronically elevated LH concentrations arc common and characterislic of women with PCOS anci are (partly) responsible for the problems associated with this syndrome ${ }^{(29)}$.

The reduction of testosterone and $\mathrm{LH}$ observed after LOD in this study, is consistent with several other previous studies ${ }^{(30)}$. Others showed that $\mathrm{LH}$ levels decreased day after ovarian surgery and 
remained low. Some studies showed that the decline is more pronounced in responders compared with non-responders. A few studies found unchanged $\mathrm{LH}$ levels wecks to months after surgery (14).

\section{B-The impact of LOD on FSH:}

In this study, the results show that Plasma concentrations of FSH did nol change after LOD.

Anovulation in PCOS is thought to be partly due to a relative intrinsic inhibition of $\mathrm{FSH}$ action ${ }^{(21)}$.

Kamel et al.(2004) and Api et al.(2005) stated that in the first wecks after surgery, FSH concentrations declined to levels comparable to baseline values before ovarian surgery $(30,31)$.

Some studies found clevaled FSH in PCO responders, in non-responders.

\section{C-The impact of LOD on AMF (The prognostic} value of AMH in women undergoing LOD):

In this study, we have demonstrated that Following LOD, there were statistically significant reduction of mean plasma concentrations of $\mathrm{AMH}$ from the pre-operalive values in the overall group of 30 women with PCOS $(8.2 \mathrm{ng} / \mathrm{ml})$ versus controls (12.2ng $/ \mathrm{ml})$. Women who ovulated after LOD ( $\mathbf{n}=$ 10) had a higher mean pre-LOD AMH level (15.5 $\mathrm{ng} / \mathrm{ml})$ compared with that $(10.5 \mathrm{ng} / \mathrm{ml})$ of patients $(n=20)$ who did not respond. The results show a statisticalfy significant reduction in LH: FSH ratio and the plasma concentrations of LH and testosterone. Plasma concentrations of FSH did not change after LOD.

The cause for reversal of the endocrinological dysfunction after ovarian surgery in PCOS is unclear. Many theories have been proposed for the cause of the rc-establishment of menstrual cycles after ovarian surgery. Originally, the removal of a mechanical barrier aflowing gonadotrophins to act more effectively. Others have suggested that surgery may cause increased blood flow to the ovaries. Others suggested reduction of local ovarian androgens with restoration of feedback to the hypothalamus and pituitary. More recent theories include gonadotrophin surge attenuating factor (GnSAF, also called gonadotrophin surge inhibiting factor: GnSIF). GnSAF is a hormone produced by the ovaries, and its function lies in regulating and suppressing $\mathrm{LH}$ secretion by reducing pituitary sensitivity. Deficiency of GnSAF in PCOS patients has been hypothesized. Another suggested reduced inhibin levels after ovarian surgery leading to increased FSH levels. Less is known about the importance of Anti-Mullarian hormone (AMH) regarding ovarian surgery in $\mathrm{PCOS}{ }^{(14)}$.

Basic research data obtained from the adult ovary indicate that AMH is mainly expressed in pre-antral and early antral follicles and has either direct or indirect roles in various phases of folliculogenesis ${ }^{(28)}$. AMH acls as a paracrine rather than a systemic factor, and thus is not part of a negative feedback loop with involvement of gonadoltopins. Thus, AMH is not influenced by the gonadotropic status and reflects only the follicle population.

Studies in mice showed that AMH lowers the sensitivity of follicles to $\mathrm{FSH}^{(1)}$, possibly contributing to deranged follicle selection. It has been suggested that aromatase activity in PCOS patients might be decreased because follicles from PCOS women do not produce large amounts of E2. AMH also inhibits aromatase activity suggesting that $\mathrm{AMH}$ contributes to the severity of PCOS (32).

In 2003, Fanchin et al; demonstrated that the antral follicle count was closely related to the serum AMH level on cycle d 3 in infertile women, in a stronger way than those obtained with other hormonal markers such as inhibin $\mathrm{B}$, estradiol, or $\mathrm{FSH}^{(20)}$.

Several teams reported on a strong increase (2- to 4-fold) of serum AMH levels in PCOS patients, in close relationship with the increase in the small antral follicular number(FN) $(19,21)$.

On the bases of these studies we can suggest that the effect of LOD could be through the reduction of number of small antral follicles leading to systemic 
and local reduction of AMH leading to increased local sensitivity to the action of FSH on the follicles, resulting in the stimulation of follicular growth and production of a dominant follicle. We recommend wide scale of research on this point

\section{INCONCLUSION}

Because AMH levels are strongly correlated with the size of the follicle pool, and because of the lack of cycle variations, serum levels of AMH are a good candidate for inclusion in standard diagnostic procedures to assess, ovarian dysfunctions, PCO. Knowledge of the serum AMH levels in such conditions might provide more insight into the possible cause or effect of altered AMH levels after LOD.

\section{REFERENCES}

1. Asuncion M, Calvo RM, San Millan JL, Sancho J, Avila S and Escobar-Morreale HF (2000): A prospective study of the prevalence of the polycystic ovarian syndrome in unselected Caucasian women from Spain. J Clin Endocrinol Metab; 85:2434-2438.

2. Hull MG (1987): Epidemiology of infertility and polycystic ovarian disease: endocrinological and demographic studies. Gynecol Endocrinol; 1: 235-245.

3. Jenny A Visser, Frank H de Jong, Joop S E Laven' and Axel P N Themmen (2006): Anti-Müllerian hormone: a new marker for ovarian function Reproduction; 131: 1-9.

4. Pigny P, Jonard S, Y. Robert Y, and Dewailly D, (2006): Serum Anti-Müllerian Hormone as a Surrogate for Antral Follicle Count for Definition of the Polycystic Ovary Syndrome, The Journal of Clinical Endocrinology \& Metabolism; 91(3): 941-945.

5. Billig H, Furuta I, Hsueh AJ, (1993): Estrogens inhibit and androgens enhance ovarian granulosa cell apoptosis. Endocrinology; 133:2204-2212.

6. Vendola K, Zhou J, Adesanay O, Wiel S Bondy C (1998): Androgens stimulate early stages of follicular growth in the primate ovary. J Clin Invest; 101:
2622-2629.

7. Hughesdon PE, (1982): Morphology and morphogenesis of the Stein Leventhal ovary and of so-called "hyperthecosis". Obstet Gynecol Surv; 37: 59-77.

8. Josso N, Cate RL, Picard JY, Vigier B, di Clemente $\mathrm{N}$, Wilson C, Imbeaud S, et al. (1993):Anti-mullerian hormone: the Jost factor. Recent Progress in Hormone Research; 48:1-59.

9. Van Rooij IA, Broekmans FJ, Scheffer GJ, Looman CW, Habbema JD, de Jong FH, Fauser BJ, Themmen APN \& Te Velde ER (2005): Serum antimullerian hormone levels best reflect the reproductive decline with age in normal women with proven fertility: a longitudinal study. Fertility and Sterility;83: 979-987.

10. Van Rooij IA, Broekmans FJ, te Velde ER, Fauser BC, Bancsi LF, de Jong FH \& Themmen APN (2002): Serum anti-Mullerian hormone levels: a novel measure of ovarian reserve. Human Reproduction;17: 3065-3071.

11. Durlinger ALL, Gruijters MJ, Kramer P, Karels B, Kumar TR, Matzuk MM, Rose UM, de Jong FH, Uilenbroek JT, Grootegoed JA \& Themmen APN (2001): Anti-Mullerian hormone attenuates the effects of FSH on follicle development in the mouse ovary. Endocrinology; 142: 4891-4899.

12. Cook CL, Siow Y, Brenner AG \& Fallat ME (2002): Relationship between serum mullerian-inhibiting substance and other reproductive hormones in untreated women with polycystic ovary syndrome and normal women. Fertility and Sterility; 77: 141-146.

13. Jonard S, Robert Y, Dewailly D(2005): Revisiting the ovarian volume as a diagnostic criterion for polycystic ovaries. Hum Reprod; 20: 2893-2898.

14. Hendriks ML, Ket JCF, Hompes PGA, Homburg R and Lambalk CB (2007): Why does ovarian surgery in PCOS help? Insight into the endocrine implications of ovarian surgery for ovulation induction in polycystic ovary syndrome. Human Reproduction Update; 13(3) :249-264.

15. Rotterdam Consensus ( 2003 ) consensus on diagnostic criteria and long-term health risks related to polycystic ovary syndrome (PCOS). Human Reproduction 19: 41-47.

16. Li TC, Saravelos H, Chow MS, Chisabingo R and Cook ID (1998):Factors affecting the outcome of laparoscopic ovarian drilling for polycystic ovarian 
syndrome in women with anovulatory infertility. $\mathrm{Br}$ J Obstet Gynaccol;105: 338-344.

17. Amer SA, Banu Z, Li TC, Ledger WL and Cooke ID (2002): Long-term follow-up of patients with polycystic ovarian syndrome after laparoscopic ovarian drilling: endocrine and ultrasonographic outcomes. Hum Reprod ; 17;: 2851-2857.

18. Amer SA, Li TC and Ledger WL (2004): Ovulation induction using laparoscopic ovarian drilling in women with polycystic ovarian syndrome: predictors of success. Hum Reprod ; 19:1719-1724.

19. Pigny P, Merlen E, Robert X, Cortet-Rudelli C, Decanter C, Jonard $S$ and Dewailly D (2003): Elevated Scrum Level of Anti-Mullerian Hormone in Patients with Polycystic Ovary Syndrome: Relationship to the Ovarian Follicle Excess and to the Follicular Arrest, The Journal of Clinical Endocrinology \& Metabolism ; 88( 12) :5957-5962.

20- Fanchin $R$, Schonauer LM, Righini C, Guibourdenche J, Frydman R \& Taieb J 2003 Serum antj-Mullerian hormone is more strongly related to ovarian follicular status than serum inhibin B, cstradiol, FSH and LH on day 3. Human Reproduclion 18: 323-327.

21. Lnven JSE, Mulders AGMGJ, Visser JA, Themmen AP. De Jong FH, Fauser BCJM (2004) AMH serum concentrations in normoovulatory and anovulatory women of reproductive age. $\mathrm{J}$ Clin Endocrinol Metab 89:318-323.

22. La Marca A, Orvieto $R$, Giulini S, Jasonni VM, Volpe A \& De Leo V 2004 Mullerian-inhibiling substance in women with polycystic ovary syndrome: relationship with hormonal and metabolic characteristics. Fertility and Sterility 82: 970-972

23. Fanchin R, Tajeb J, Lozano DH, Ducot B, Frydman $R$, Bouyer J ( 2005) High reproducibility of serum AMH measurements suggests a multi-staged follicular secretion and strengthens its role in the assessment of ovarian follicular status. Hum Reprod 20: 923-927.

24. Eldar-Geva T, Margalioth EJ, Gal M, Ben-Chetrit A, Algur N, Zylber-Haran E, Brooks B, Huerta M \& Spitz IM 2005 Serum anti-Mullerian hormone levels during controlled ovarian hyperstimulation in women with polycystic ovaries with and without hyperandrogenism. Human Reproduction 20 1814-1819.

25. Rey R, Lordereau-Richard I, Carel JC, Barbet P. Cate RL, Roger M, Chaussain JL \& Josso N (1993) Anti-mullerian hormone and testosterone serum levels are inversely related during normal and precocious pubertal development. Journal of Clinical Endocrinology and Metabolism 7: 1220-1226.

26. Jonard S, Dewailly D (2004) The follicular excess in polycystic ovaries due 10 intra-ovarian hyperandrogenism, may be the culprit for the follicular arrest. Hum Reprod Update 2:1-11.

27. Weenen C, Laven ISE, von Bergh ARM, Cranfield M, Groome NP, Visser JA, Kramer P, Fauser BCJM, Themmen APN (2004) Anti-Mullerian hormone expression pattern in the human ovary: potential implications for initial and cyclic follicle recruitment. Mol Hum Reprod 10: 77-83.

28. Josso $N$, di Clemente $N$, Gouedard L (2001) Anti-Mullerian hormone and its receptors. Mol Cell Endocrinol 179:25-32.

29. Van Santbrink EJ, Hop WC and Fauser BC (1997) Classification of normogonadotropic infertility: polycystic ovaries diagnosed by ultrasound versus endocrine characteristics of polycystic ovary syndrome. Fertil Steril 67,452-458.

30. Kamel MA, Abdel Hamid AED, Abdel-Rahim M and Mostafa SA (2004): Laparoscopic ovarian re-electro cautery versus ovulation induction with FSH for persistant anovulation after laparoscopic PCOS treatment.Middle East Fertil Soc J 9,70-778.

30. Felemban A, Tar SL and Tulandi $T$ (2000) Laparoscopic treatment of polycystic ovaries with insulated needle cautery: a reappraisal. Fertil Steril 73: $26-269$.

31. Api M, Gorgen $H$ and Celin A (2005) Laparoscopic ovarian drilling in polycystic ovary syndrome. Eur $\mathrm{J}$ Obstet Gynecol Reprod Biol 119, 76-81.

32. Agrawal R, Sladkevicius P, Engmann L, Conway GS, Payne NN, Bekis J, Tan SL, Campbell S and Jacobs HS (1998) Serum vascular endothelial growth factor concentrations and ovarian stromal blood flow are increased in women with polycystic ovaries. Hum Reprod 13, 651-655. 